\title{
Viabilidade econômica de um sistema de produção de pecuária bovina sob alta lotação: uso na pesquisa e na pecuária comercial ${ }^{1}$
}

\author{
Economic viability of a cattle system production under high stocking rate: use in \\ research and commercial livestock
}

\author{
RODRIGUES, Rinaldo ${ }^{2 *}$; GAMEIRO, Augusto Hauber²; PRADA E SILVA, Luis \\ Felipe $^{2}$; ALVES, Teresa Cristina ${ }^{3}$
}

\author{
${ }^{1}$ Parte de dissertação de mestrado do primeiro autor. \\ ${ }^{2}$ Universidade de São Paulo, Faculdade de Medicina Veterinária e Zootecnia, Departamento de Nutrição e \\ Produção Animal. \\ ${ }^{3}$ Empresa Brasileira de Pesquisa Agropecuária, Embrapa Pecuária Sudeste. \\ *Endereço para correspondência: rr_agro@terra.com.br
}

\section{RESUMO}

Um estudo de viabilidade foi desenvolvido para verificação da economicidade de um sistema de produção de ciclo completo de pecuária de bovinos de corte, sob alta lotação, concebido para a utilização em pesquisas na FMVZ/USP. Foram utilizados nove cenários - definidos a partir da variação de preços dos produtos vendidos e utilização de capital próprio e de recursos de financiamento rural via Programas do BNDES. Adicionalmente, utilizou-se um décimo cenário - considerando o arrendamento de área liberada a partir da intensificação do sistema de produção. O método de análise econômica utilizado foi o de Fluxo de Caixa e as técnicas aplicadas foram: Payback Simples, Payback Descontado, Valor Presente Líquido e Taxa Interna de Retorno. O sistema mostrou-se economicamente viável estritamente para o cenário que considerou o nível máximo de projeção de preços da arroba da carne e para o cenário que considerou o arrendamento de área liberada a partir da intensificação do sistema de produção. A utilização de financiamento via Programa de Crédito Rural do BNDES proporcionou melhora expressiva nos resultados e índices utilizados na análise.

\section{SUMMARY}

A feasibility study was carried out to verify the economic viability of a production system lifecycle livestock production of beef cattle under high stocking. This was designed for use in research in the Faculty of Veterinary Medicine, University of São Paulo. Therefore, was used nine scenarios - determined from the variation of prices of products sold and use of capital and resources in rural finance programs (BNDES). Was used also a scenario - considering the leasing of the area released from the intensification of production systems. The analysis method used was Cash Flow and the applied techniques were: Simple Payback, Discounted Payback, Net Present Value (NPV) and Internal Rate of Return (IRR). The system showed to be economically viable for the scenarios that considered the maximum projection of weight meat of prices and to scenario considered that was leasing from the intensification of production systems. The use of funding via the Rural Credit Program BNDES has provided significant improvement in the values and indices used in the analysis.

Keywords: beef cattle, cash flow, economy

Palavras-chave: bovinocultura, economia, fluxo de caixa 


\section{INTRODUÇÃO}

Embora a aparente supremacia da bovinocultura brasileira, sabe-se que essa se caracteriza pela utilização de modelos de produção ditos extensivos. De eficiência questionável, esses modelos baseiam-se na exploração das atividades em grandes áreas geográficas com pouca utilização de tecnologias avançadas de produção. Da utilização de novas tecnologias, melhorias do potencial de resposta dos animais e da necessidade da exploração racional dos recursos de produção surgiram sistemas mais especializados, denominados intensivos. Esses, quando considerados sistematicamente podem constituir alternativa sustentável da atividade pecuária.

A importância do setor na economia e as demandas relacionadas à sustentabilidade dos sistemas produtivos apontam para que entidades organizacionais públicas e privadas ocupem parte de seus esforços e investimentos na pesquisa e aplicação de alternativas tecnológicas que tornem a produção mais eficiente. Exemplos recentes de pesquisas que procederam com avaliações econômicas são: Amaral et al. (2011), Assumpção et al. (2011), Lima et al. (2011), Martins et al. (2011), Rebouças et al. (2010) e Rocha Neto et al. (2010). Inúmeras pesquisas são conduzidas com vistas ao aumento da produtividade dos rebanhos, porém notase que nem sempre as tecnologias de produção são estudadas interativamente. Assim, o conjunto isolado de dados e informações podem ser insuficientes para responder questionamentos relacionados à viabilidade de empreendimentos com diferentes graus de utilizações das tecnologias de produção.

A fim de propiciar a realização de pesquisas zootécnicas na área de bovinocultura de corte pelo Departamento de Nutrição e Produção Animal, da Faculdade de Medicina Veterinária e Zootecnia da Universidade de São Paulo, projetou-se um sistema de produção no qual as tecnologias pudessem ser estudadas interativamente. $\mathrm{O}$ planejamento e a execução do empreendimento suscitaram o questionamento de que se tal sistema de produção - com a utilização da mesma infraestrutura e tecnologias de produção - poderia ser viável economicamente para a aplicação na bovinocultura de corte com fins comercias.

Objetivou-se com este trabalho verificar a viabilidade econômica de tal sistema de produção e o efeito do incremento da utilização das tecnologias de produção (intensificação do sistema).

\section{MATERIAL E MÉTODOS}

O sistema foi implantado no Campus de Pirassununga (Figura 1), onde projetou-se a produção de bovinos de corte com alta utilização das tecnologias de produção no seu ciclo completo: cria, recria e terminação, dividindo-se a gleba conforme a sua utilização (Tabela 1).

A estratégia de produção foi determinada para criação de animais sob pastejo e terminação por meio de confinamento, e o layout das áreas de manejo e confinamento foi implantado conforme apresenta a Figura 2.

A avaliação econômica do empreendimento resultou do levantamento e sistematização do conjunto de informações: dos recursos necessários para a sua execução, das tecnologias a serem aplicadas na produção e obtenção dos produtos, e das receitas monetárias previstas.

A análise foi realizada por meio dos fluxos de caixa estimados para o empreendimento, obtidos de forma 
Rev. Bras. Saúde Prod. Anim., Salvador, v.13, n.1, p.244-257 jan/mar, 2012 http://www.rbspa.ufba.br ISSN 15199940

direta ao serem rastreadas as entradas e saídas de caixa previstas de disponibilidades. Os fluxos de caixa foram construídos para os anos calendários de 2009 (ano um) até 2038 (ano 30).

As entradas de caixa decorreram de três situações, a saber: das receitas brutas anuais resultantes da comercialização dos animais; da entrada de caixa decorrente de operação de crédito rural, com recursos do BNDES; e da receita de arrendamento da terra. A receita bruta foi obtida da multiplicação do número de animais disponíveis para a comercialização pelo valor monetário estipulado por categoria (RODRIGUES, 2010).

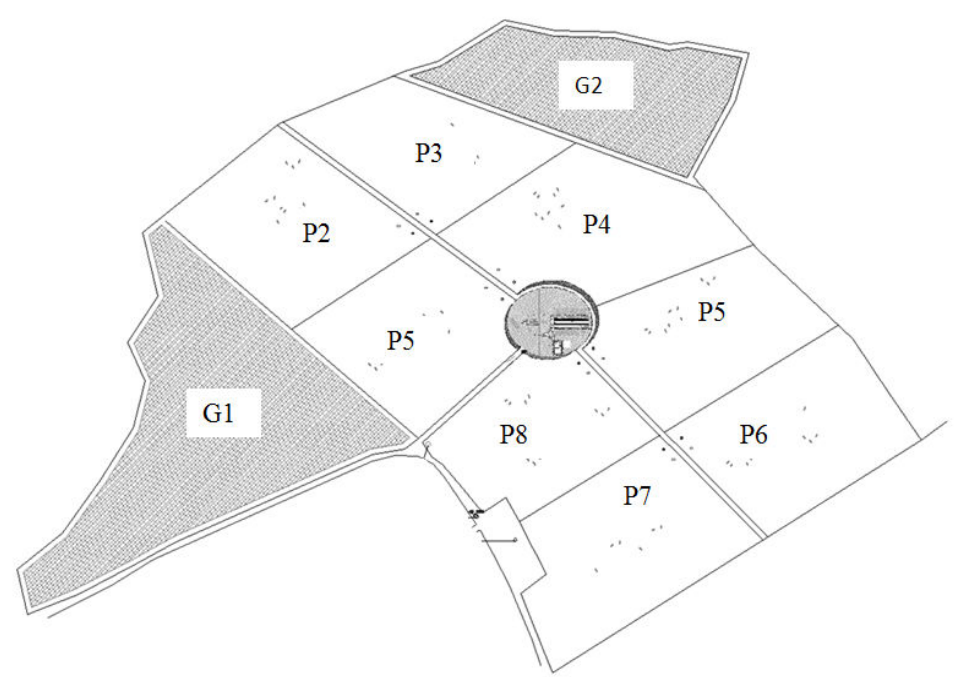

Figura 1. Implantação do layout de operações

Tabela 1. Identificação, descrição e áreas da gleba

\begin{tabular}{llcl}
\hline Id. Glebas & Descrição & Área (ha) & Utilização \\
\hline P1 & Piquete 1 & 2,08 & Panicum maximum cv Mombaça \\
P2 & Piquete 2 & 1,86 & Panicum maximum cv Mombaça \\
P3 & Piquete 3 & 1,72 & Brachiaria brizantha cv Marandu \\
P4 & Piquete 4 & 2,30 & Brachiaria brizantha cv Marandu \\
P5 & Piquete 5 & 1,74 & Brachiaria brizantha cv Marandu \\
P6 & Piquete 6 & 2,19 & Brachiaria brizantha cv Marandu \\
P7 & Piquete 7 & 1,95 & Panicum maximum cv Mombaça \\
P8 & Piquete $~$ & 2,12 & Panicum maximum cv Mombaça \\
G1 & Gleba 1 & 3,98 & Cana de açúcar \\
G2 & Gleba 2 & 2,05 & Reserva \\
Outras 1 & Estradas e carreadores & 1,26 & Estradas e carreadores \\
Outras 2 & Instalações & 0,42 & Área de manejo e confinamento \\
\hline Total & & 23,67 & \\
\hline
\end{tabular}




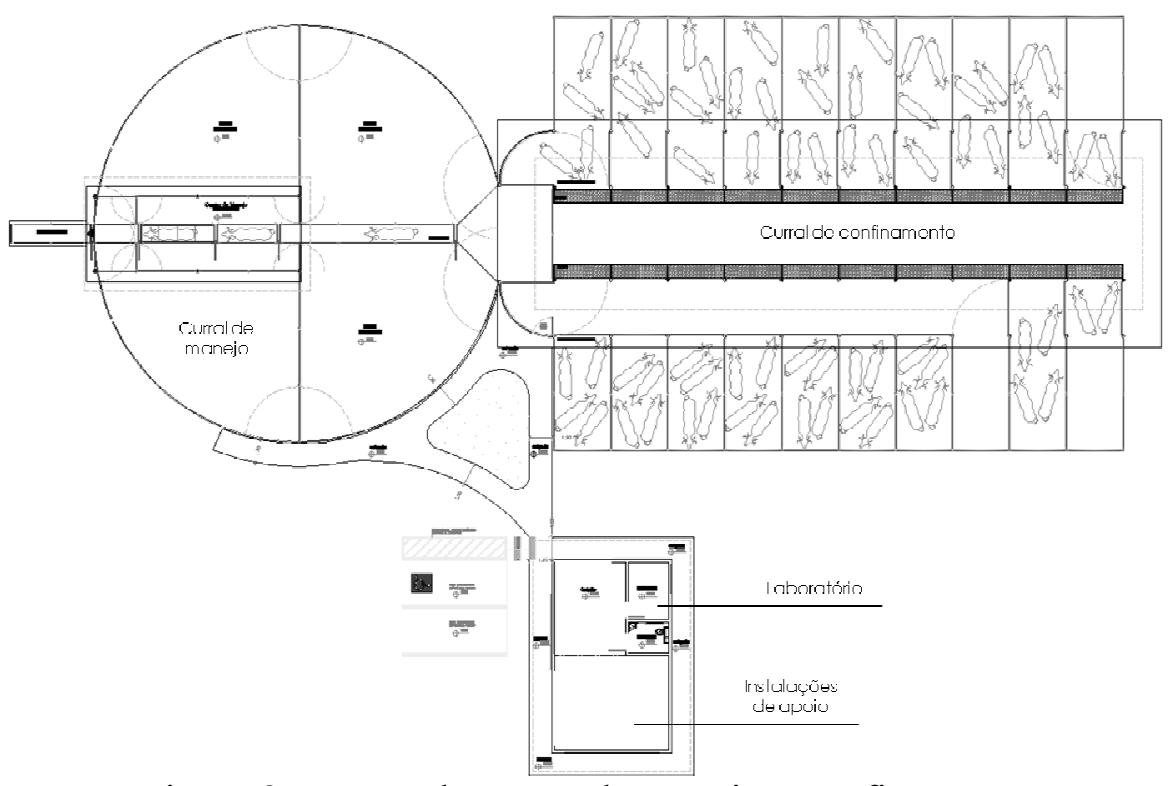

Figura 2. Layout das áreas de manejo e confinamento

Com relação aos preços dos animais comercializados utilizaram-se como referência os preços diários, à vista, pagos aos produtores - por arroba de carne - para o estado de São Paulo, fornecidos pelo Centro de Estudos Avançados em Economia Aplicada (CEPEA). O período de coleta dos dados foi de 01 de janeiro de 2000 até o dia 28 de julho de 2010 (CEPEA, 2010). As médias mensais dos preços nominais diários foram obtidas para todos os meses do período analisado. Após, deflacionou-se as médias nominais mensais de forma a atualizálas para valores reais equivalentes a julho de 2010, conforme metodologia tradicional apresentada por Viana et al. (2009) e com a utilização da Equação (1):

$$
P R t=\frac{P N t \times I P a}{I P t}
$$

Em que: $P R t=$ Preço Real no mês " $\mathrm{t}$ "; $P N t=$ Preço Nominal corrigido no mês "t"; $I P a$ = IGP-DI de julho de 2010; e $I P t=$ IGP-DI no mês " $\mathrm{t}$ ".
Para o deflacionamento dos preços utilizou-se o Índice Geral de Preços (IGP-DI), calculado pela Fundação Getúlio Vargas (FGV, 2010). Para a simulação das variações das receitas nos fluxos de caixa utilizou-se as médias mínima, geral e máxima - anuais corrigidas, conforme apresentadas na Figura 3.

Os valores das médias encontrados foram: média anual mínima de R\$ 66,06/@; média geral R\$81,17/@e média anual máxima R\$90,67/@. Neste trabalho são denominadas: nível mínimo, nível médio e nível máximo, respectivamente.

Os critérios para estabelecimento dos valores de venda por categoria animal foram: fêmeas não prenhes, com mais de 36 meses de idade, peso bruto de $450 \mathrm{~kg}$, com $53 \%$ de aproveitamento de carcaça, pagamento de $100 \%$ do preço da arroba de carne para a categoria fêmea; fêmeas não prenhes, de 24 a 36 meses de idade, peso bruto de $410 \mathrm{~kg}$, com 53\% de aproveitamento de carcaça, pagamento de $100 \%$ do preço da arroba de carne para a categoria fêmea; fêmeas não prenhes, de 12 a 24 meses de idade, 
peso bruto de $360 \mathrm{~kg}$, com $53 \%$ de aproveitamento de carcaça, pagamento de $100 \%$ do preço da arroba de carne para a categoria fêmea; fêmeas prenhes, com mais de 36 meses de idade, peso bruto de $450 \mathrm{~kg}$, pagamento de $100 \%$ do preço da arroba de carne para a categoria fêmea, com ágio de 3 arrobas de carne para a categoria macho; fêmeas prenhes, de 12 a 24 meses de idade, peso bruto de $360 \mathrm{~kg}$, pagamento de $100 \%$ do preço da arroba de carne para a categoria macho, com ágio de três arrobas de carne para a categoria macho; machos de zero a 12 meses de idade, peso bruto de $210 \mathrm{~kg}$, pagamento de $100 \%$ do preço da arroba de carne para a categoria macho, com ágio de $25 \%$ no preço da arroba de carne para a categoria macho; machos de 12 a 24 meses de idade, peso bruto de $460 \mathrm{~kg}$, com 53\% de aproveitamento de carcaça, pagamento de $100 \%$ do preço da arroba de carne para a categoria macho.

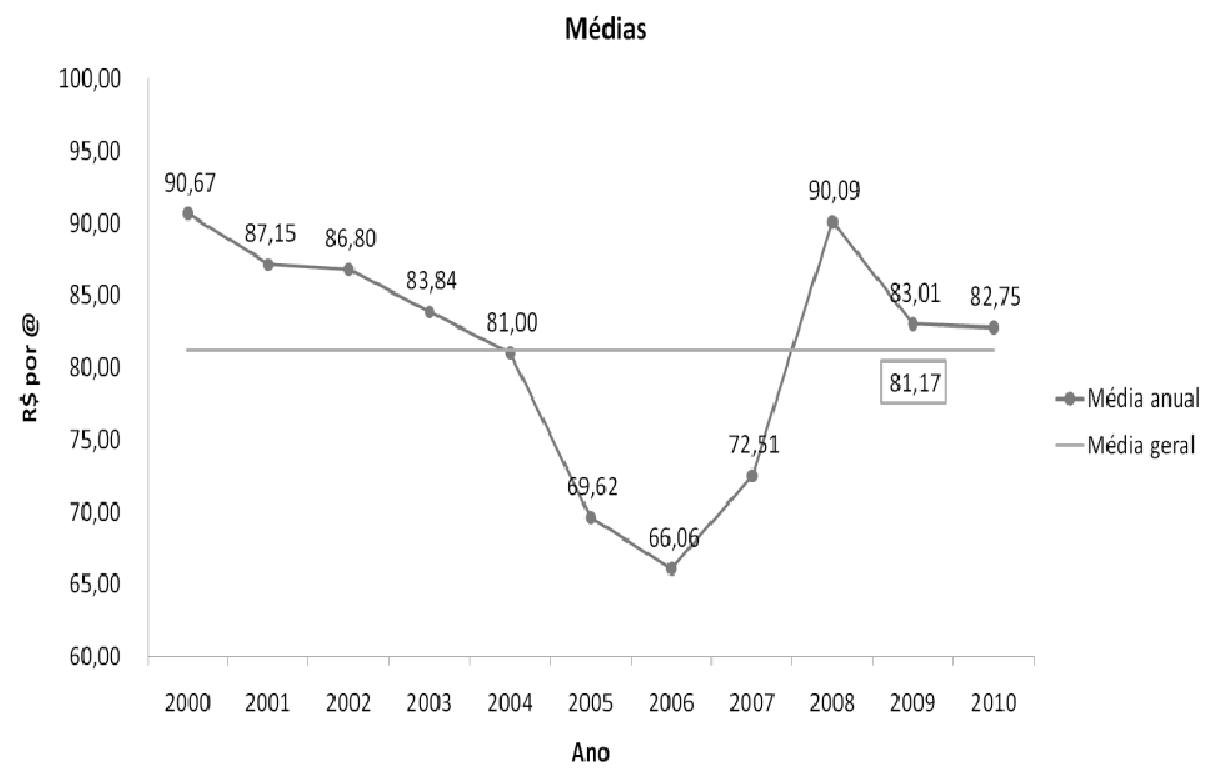

Figura 3. Médias anuais dos preços corrigidos - 2000-2010

A projeção dos fluxos de caixa com a utilização de capital de terceiros foi realizada por meio de simulação de operação de crédito rural. Os parâmetros utilizados foram os fornecidos com base nos programas agropecuários do governo federal administrados pelo BNDES, via instituições conveniadas (BNDES, 2010).

Para efeito de lançamento nos fluxos de caixa, foram definidas duas situações derivadas de empréstimo para pessoa física, no limite estabelecido pelo programa denominado Programa de Estímulo à Produção Agropecuária Sustentável (PRODUSA): pagamento dos juros incorporados ao valor inicial da dívida após o período de carência (Tabela 2); e pagamento dos juros devidos no período de carência (Tabela 3).

Torna-se importante esclarecer que as instituições financeiras conveniadas têm cada qual sua política e aspectos normativos específicos para a concessão do crédito. Deste modo, as bases e critérios próprios das instituições 
Rev. Bras. Saúde Prod. Anim., Salvador, v.13, n.1, p.244-257 jan/mar, 2012 http://www.rbspa.ufba.br ISSN 15199940

conveniadas - como prazos, garantias, limites dentre outras exigências - são somados às restrições e aplicações dos programas do governo federal. Portanto a existência dos programas de financiamento governamental não garante o acesso aos mesmos.

Tabela 2. Saldo devedor, prestação, juros e amortizações decorrentes de operação de crédito rural com pagamento dos juros incorporados ao valor inicial da dívida após o período de carência

\begin{tabular}{lccccc}
\hline Ano $(\mathrm{n})^{1}$ & Ano $^{2}$ & Saldo devedor $^{3}$ & Prestação & Juros $^{4}$ & Amortização $^{5}$ \\
\hline 1 & 2009 & - & - & - & - \\
2 & 2010 & $300.000,00$ & - & - & - \\
3 & 2011 & $320.250,00$ & - & - & - \\
4 & 2012 & $341.866,88$ & - & - & - \\
5 & 2013 & $364.942,89$ & - & - & - \\
6 & 2014 & $329.051,15$ & $60.525,38$ & $24.633,65$ & $35.891,73$ \\
7 & 2015 & $290.736,73$ & $60.525,38$ & $22.210,95$ & $38.314,43$ \\
8 & 2016 & $249.836,08$ & $60.525,38$ & $19.624,73$ & $40.900,65$ \\
9 & 2017 & $206.174,63$ & $60.525,38$ & $16.863,94$ & $43.661,44$ \\
10 & 2018 & $159.566,04$ & $60.525,38$ & $13.916,79$ & $46.608,59$ \\
11 & 2019 & $109.811,37$ & $60.525,38$ & $10.770,71$ & $49.754,67$ \\
12 & 2020 & $56.698,25$ & $60.525,38$ & $7.412,27$ & $53.113,11$ \\
13 & 2021 & 0,00 & $60.525,38$ & $3.827,13$ & $56.698,25$ \\
\hline
\end{tabular}

Nota: $\mathrm{i}=6,75 \%$ ao ano.

${ }^{1}$ Ano do projeto; ${ }^{2}$ Ano calendário; ${ }^{3} \mathrm{SD}_{\mathrm{n}}=\mathrm{SD}_{\mathrm{n}-1}-\mathrm{Na} ;{ }^{4} \mathrm{~J}_{\mathrm{n}}=\mathrm{SD}_{\mathrm{n}-1} \mathrm{x} \mathrm{i} ;{ }^{5} \mathrm{~A}_{\mathrm{n}}=\mathrm{PMT}_{\mathrm{n}}-\mathrm{J}_{\mathrm{n}}$.

Tabela 3. Saldo devedor, prestação, juros e amortizações decorrentes de operação de crédito rural com pagamento dos juros devidos no período de carência

\begin{tabular}{lccccc}
\hline Ano (n) & Ano $^{2}$ & Saldo devedor $^{3}$ & Prestação & Juros $^{4}$ & Amortização $^{5}$ \\
\hline 1 & 2009 & - & - & - & - \\
2 & 2010 & $300.000,00$ & - & - & - \\
3 & 2011 & $300.000,00$ & $20.250,00$ & $20.250,00$ & - \\
4 & 2012 & $300.000,00$ & $20.250,00$ & $20.250,00$ & - \\
5 & 2013 & $300.000,00$ & $20.250,00$ & $20.250,00$ & - \\
6 & 2014 & $270.495,33$ & $49.754,67$ & $20.250,00$ & $29.504,67$ \\
7 & 2015 & $238.999,09$ & $49.754,67$ & $18.258,43$ & $31.496,24$ \\
8 & 2016 & $205.376,86$ & $49.754,67$ & $16.132,44$ & $33.622,23$ \\
9 & 2017 & $169.485,13$ & $49.754,67$ & $13.862,94$ & $35.891,73$ \\
10 & 2018 & $131.170,71$ & $49.754,67$ & $11.440,25$ & $38.314,42$ \\
11 & 2019 & $90.270,06$ & $49.754,67$ & $8.854,02$ & $40.900,65$ \\
12 & 2020 & $46.608,62$ & $49.754,67$ & $6.093,23$ & $43.661,44$ \\
13 & 2021 & 0,00 & $49.754,67$ & $3.146,08$ & $46.608,59$ \\
\hline
\end{tabular}

Nota: $i=6,75 \%$ ao ano.

${ }^{1}$ Ano do projeto; ${ }^{2}$ Ano calendário; ${ }^{3} \mathrm{SD}_{\mathrm{n}}=\mathrm{SD}_{\mathrm{n}-1}-\mathrm{A}_{\mathrm{n}} ;{ }^{4} \mathrm{~J}_{\mathrm{n}}=\mathrm{SD}_{\mathrm{n}-1} \mathrm{x}$ i; ${ }^{5} \mathrm{~A}_{\mathrm{n}}=\mathrm{PMT}_{\mathrm{n}}-\mathrm{J}_{\mathrm{n}}$. 
As saídas de caixa foram projetadas a partir dos investimentos iniciais decorrentes da implantação da infraestrutura, dos gastos com a manutenção e reforma da lavoura de cana-de-açúcar, dos gastos com a manutenção das pastagens e dos gastos com o manejo do rebanho nos seus vários aspectos.
Obtiveram-se nove possíveis combinações para a análise, a partir dos preços nominais corrigidos nos períodos determinados e das opções de investimento com recursos próprios e de terceiros. As possíveis combinações foram denominadas cenários, conforme apresentado na Tabela 4.

Tabela 4. Cenários para a determinação da viabilidade econômica do empreendimento

\begin{tabular}{|c|c|c|c|c|}
\hline \multirow[b]{2}{*}{ Nível de preço } & \multicolumn{4}{|c|}{ Fonte de recursos } \\
\hline & Próprios & Próprios e CR $1^{1}$ & Próprios e CR $2^{2}$ & $\begin{array}{c}\text { Próprios e } \\
\text { Arrendamento }\end{array}$ \\
\hline Mínimo ${ }^{3}$ & Cenário 1 & Cenário 2 & Cenário 3 & - \\
\hline Médio $^{4}$ & Cenário 4 & Cenário 5 & Cenário 6 & Cenário 10 \\
\hline Máximo 5 & Cenário 7 & Cenário 8 & Cenário 9 & - \\
\hline
\end{tabular}

${ }^{1}$ Saldo devedor, prestação, juros e amortizações decorrentes de operação de crédito rural com pagamento dos juros incorporados ao valor inicial da dívida após o período de carência; ${ }^{2}$ Saldo devedor, prestação, juros e amortizações decorrentes de operação de crédito rural com pagamento dos juros devidos no período de carência; ${ }^{3}$ Nível mínimo: R\$66,06/@; ${ }^{4}$ Nível médio: R\$81,17/@; ${ }^{5}$ Nível máximo: R\$90,67/@.

Incluiu-se o cenário 10 pelo fato de que um dos principais motivadores - se não o principal - da utilização do sistema sob alta lotação na pecuária comercial é a possibilidade do uso intensivo da terra, ao permitir a produção de um determinado número de animais em uma área reduzida. Neste cenário considerou-se a lotação máxima de 132UA em 15,96ha, para estabilização do rebanho sob pastejo no sistema de produção proposto. Ao se admitir 1,22UA/ha como a taxa de lotação (média de lotação animal para os meses de verão e de inverno) do sistema sob pastejo para a pecuária tradicional seriam necessários 108,20 ha para o desenvolvimento da atividade na situação dita "extensiva", para a produção do mesmo nível obtido no sistema proposto. Como a área total na qual foi planejado o sistema sob alta lotação foi de 23,67ha, a opção pela implantação do sistema possibilitaria a liberação de 84,53ha de terra. Especificamente para a região onde o sistema foi planejado, o arrendamento da terra para o cultivo da cana-deaçúcar por parte das usinas sucroalcooleiras apresentou-se como oportunidade para utilização da terra. A opção pelo arrendamento da área gerou uma renda anual no horizonte de tempo da análise e considerada a partir da entrega da terra para o arrendatário, a partir do ano de 2010.

As técnicas de análise utilizadas foram:

Período de Payback Simples (PBS)

Representa o número de períodos necessários para que a soma dos benefícios econômicos se iguale à soma dos dispêndios. Pode ser representado pela Equação (2): 


$$
P R=T \text { quando } \sum_{t=0}^{T} F C_{t}=10
$$

Em que:

PR é o período de recuperação;

$\mathrm{FC}_{\mathrm{t}}$ é o fluxo de caixa total no período $\mathrm{t}$; e

$\mathrm{I}_{\mathrm{o}}$ é o fluxo de caixa inicial do investimento.
Técnica do Payback Descontado

A técnica do Payback Descontado é similar ao Payback Simples, porém considera uma taxa de atratividade ou de desconto. Desta forma, adicionandose o custo de capital, considera-se o valor do dinheiro no tempo (Tabela 5).

Tabela 5. Fluxo de caixa para cálculo do Payback Descontado de um projeto de seis anos

\begin{tabular}{lccccccc}
\hline \multicolumn{1}{c}{ Ano } & 0 & 1 & 2 & 3 & 4 & 5 & 6 \\
\hline Fluxos de caixa & -200.000 & 40.000 & 45.000 & 60.000 & 65.000 & 50.000 & 35.000 \\
Valor presente & -200.000 & 36.364 & 37.190 & 45.079 & 44.396 & 31.046 & 19.756 \\
Valor acumulado & -200.000 & -163.636 & -126.446 & -81.367 & -36.971 & -5.926 & 13.831 \\
\hline
\end{tabular}

Taxa de desconto considerada: $10 \%$ aa.

Técnica do Valor Presente Líquido

O Valor Presente Líquido (VPL) é obtido subtraindo-se o investimento inicial (II) do valor presente das entradas de caixa $\left(\mathrm{FC}_{\mathrm{t}}\right)$, descontadas a uma taxa igual ao custo de capital da empresa $(k)$, e mostrado pela Equação 3:

$$
V P L=F C o+\sum_{t=1}^{n} \frac{F C_{t}}{(1+k)^{t}}
$$

Em que:

VPL é o valor presente líquido;

$\mathrm{FC}_{\mathrm{o}}$ é o fluxo de caixa total no tempo 0;

$\mathrm{FC}_{\mathrm{t}}$ é o fluxo de caixa total no período t;

$\mathrm{k}$ é a taxa de desconto;

$\mathrm{t}=$ é o número de períodos a que se refere o fluxo de caixa.

Técnica da Taxa Interna de Retorno É definida como a taxa de desconto que iguala o valor presente das entradas de caixa ao investimento inicial. $\mathrm{O}$ autor define a taxa interna de retorno (TIR) como a taxa de retorno que iguala o valor presente das entradas dos fluxos de caixa ao investimento inicial referente a um investimento ou projeto. Matematicamente, a TIR é obtida resolvendo-se a Equação 3 para o valor de $k$ que torne o VPL igual a zero, conforme apresenta a Equação 4:

$$
0=F C o+\sum_{t=1}^{n} \frac{F C_{t}}{(1+k)^{t}}
$$

Em que:

$\mathrm{FC}_{\mathrm{o}}$ é o fluxo de caixa total no tempo 0 ; $\mathrm{FC}_{t}$ é o fluxo de caixa total no período t; $\mathrm{k}$ é o valor da TIR que iguala o VPL a zero; e

$\mathrm{n}=$ é o número de períodos a que se refere o fluxo de caixa.

Os cálculos foram realizados com a utilização de planilha eletrônica Microsoft ${ }^{\circledR}$ Office Excel®. Para a obtenção da taxa interna de retorno, quando da ocorrência de fluxos de caixa não convencionais utilizou-se a metodologia proposta por Barbieri et al. (2007). Esta metodologia propõe que os fluxos de caixa intermediários positivos sejam levados para a data final do projeto e os fluxos de caixa negativos para a data inicial do mesmo. Ao se 
combinar esses procedimentos tem-se um fluxo de caixa convencional. Esse novo parâmetro do fluxo de caixa do projeto foi denominado Taxa Interna de Retorno Modificada (TIRM).

\section{RESULTADOS E DISCUSSÃO}

Os resultados completos estão apresentados na Tabela 5. O quarto cenário (Tabela 6) pode ser considerado o mais realista em termos de nível preço esperado. O décimo cenário (Tabela 7) representa a opção de arrendamento da área liberada com a intensificação da pecuária.

Para a variação nos preços da arroba utilizaram-se três níveis, o mínimo, o médio e o máximo. Deve-se ressaltar que os cenários nos quais foi utilizado o nível médio de preços $(4,5$ e 6$)$ da arroba são os mais realistas. Nos cenários nos quais foi utilizado o nível mínimo de preços (1, 2 e 3$)$ procurou-se representar situações em que os preços relativos dos fatores de produção subiriam mais que proporcionalmente aos preços da carne. Nos cenários de nível máximo de preços $(7,8$ e 9$)$ procurou-se a representação extrema e contrária à situação apresentada nos cenários de nível mínimo de preços.

A utilização de financiamento impactou sobremaneira os resultados obtidos para os cenários de nível médio de preços $(4,5$ e 6) e criou uma situação crítica para a aceitação ou não do projeto. Se utilizados os critérios de decisão para aceitar/rejeitar o projeto, o empreendimento não seria viável economicamente. Porém notou-se que o valor presente líquido e a taxa interna de retorno para os cenários 5 e 6 , nos quais utilizou-se o financiamento, aproximou-se dos limites para os critérios de aceitação. Nessa situação o Payback Simples, embora considerado uma técnica limitada, apresenta-se importante. Nota-se que nessa situação o número de períodos (16 anos) - Payback Simples - pode sinalizar como uma medida de risco associada ao tempo de retorno. (BALARINE, 2004).

Tabela 5. Determinação da viabilidade econômica do empreendimento, a partir das diferentes técnicas de análise para os diferentes cenários propostos

\begin{tabular}{cccccc}
\hline Cenário & $\begin{array}{c}\text { Ano Payback } \\
\text { Simples }\end{array}$ & $\begin{array}{c}\text { Ano Payback } \\
\text { Descontado }\end{array}$ & $\begin{array}{c}\text { VPL } \\
(\mathrm{i}=10,75 \%)\end{array}$ & TIR & TIRM $^{1}$ \\
\hline 1 & $18^{\mathrm{o}}$ & - & $-234.839,89$ & 4,74 & - \\
2 & $23^{\mathrm{o}}$ & - & $-167.809,35$ & $3,61 ?$ & 7,11 \\
3 & $23^{\mathrm{o}}$ & - & $-177.258,23$ & $3,82 ?$ & 7,50 \\
4 & $13^{\mathrm{o}}$ & - & $-83.491,57$ & 8,95 & - \\
5 & $16^{\mathrm{o}}$ & - & $-7.461,02$ & $10,45 ?$ & 10,62 \\
6 & $16^{\mathrm{o}}$ & - & $-16.909,91$ & $10,14 ?$ & 10,42 \\
7 & $11^{\mathrm{o}}$ & $27^{\mathrm{o}}$ & $17.323,07$ & 11,10 & - \\
8 & $14^{\mathrm{o}}$ & $19^{\mathrm{o}}$ & $93.353,61$ & 14,35 & - \\
9 & $14^{\mathrm{o}}$ & $20^{\mathrm{o}}$ & $83.904,73$ & 13,65 & - \\
10 & $6^{\mathrm{o}}$ & $7^{\mathrm{o}}$ & $861.288,55$ & 32,29 & - \\
\hline
\end{tabular}

Nota: Sinais convencionais utilizados: ... Dado numérico não disponível; ? Dúvida quanto à exatidão do valor dado; Não se aplica dado numérico.

${ }^{1}$ Metodologia proposta por Barbieri, 2007, p 137. 
Tabela 6. Projeção dos fluxos de caixa do empreendimento com a utilização de recursos próprios e receita bruta auferida a partir da venda de animais com a utilização da média geral dos preços corrigidos - 2009-2038. Cenário 4

\begin{tabular}{|c|c|c|c|c|c|c|c|c|}
\hline $\mathrm{AP}^{1}$ & $\mathrm{AC}^{2}$ & $\mathrm{ESC}^{3}$ & $\mathrm{RB}^{4}$ & $\mathrm{D}^{5}$ & $\mathrm{FCL}^{6}$ & FCL $\left(\mathrm{AND}^{7}\right)$ & $\mathrm{FCL}\left(\mathrm{D}^{8}\right)$ & FCL $\left(\mathrm{AD}^{9}\right)$ \\
\hline 1 & 2009 & - & - & $-12.435,99$ & $-12.435,99$ & $-12.435,99$ & $-15.253,44$ & $-15.253,44$ \\
\hline 2 & 2010 & - & - & $-314.498,39$ & $-303.794,39$ & $-316.230,37$ & $-336.452,28$ & $-351.705,72$ \\
\hline 3 & 2011 & - & $12.002,61$ & $-213.900,92$ & $-199.650,47$ & $-515.880,85$ & $-199.650,47$ & $-551.356,19$ \\
\hline 4 & 2012 & - & $71.359,44$ & $-56.084,89$ & $15.274,55$ & $-500.606,29$ & $13.791,92$ & $-537.564,27$ \\
\hline 5 & 2013 & - & $117.563,80$ & $-56.992,58$ & $60.571,22$ & $-440.035,07$ & $49.383,16$ & $-488.181,12$ \\
\hline 6 & 2014 & - & $121.549,59$ & $-59.956,30$ & $61.593,29$ & $-378.441,78$ & $45.342,16$ & $-442.838,95$ \\
\hline 7 & 2015 & - & $120.838,44$ & $-57.044,76$ & $63.793,68$ & $-314.648,10$ & $42.403,60$ & $-400.435,35$ \\
\hline 8 & 2016 & - & $115.614,09$ & $-57.493,19$ & $58.120,90$ & $-256.527,19$ & $34.882,99$ & $-365.552,36$ \\
\hline 9 & 2017 & - & $115.822,51$ & $-68.292,85$ & $47.529,66$ & $-208.997,54$ & $25.757,42$ & $-339.794,95$ \\
\hline 10 & 2018 & - & $115.822,51$ & $-57.698,79$ & $58.123,72$ & $-150.873,82$ & $28.441,16$ & $-311.353,79$ \\
\hline 11 & 2019 & - & $115.822,51$ & $-57.045,19$ & $58.777,32$ & $-92.096,50$ & $25.969,28$ & $-285.384,51$ \\
\hline 12 & 2020 & - & $115.822,51$ & $-57.698,79$ & $58.123,72$ & $-33.972,78$ & $23.187,81$ & $-262.196,70$ \\
\hline 13 & 2021 & - & $115.822,51$ & $-57.045,19$ & $58.777,32$ & $24.804,54$ & $21.172,51$ & $-241.024,19$ \\
\hline 14 & 2022 & - & $115.822,51$ & $-57.495,81$ & $58.326,70$ & $83.131,24$ & $18.970,83$ & $-222.053,36$ \\
\hline 15 & 2023 & - & $115.822,51$ & $-57.045,19$ & $58.777,32$ & $141.908,56$ & $17.261,76$ & $-204.791,60$ \\
\hline 16 & 2024 & - & $115.822,51$ & $-57.698,79$ & $58.123,72$ & $200.032,28$ & $15.412,92$ & $-189.378,69$ \\
\hline 17 & 2025 & - & $115.822,51$ & $-68.292,85$ & $47.529,66$ & $247.561,94$ & $11.380,27$ & $-177.998,42$ \\
\hline 18 & 2026 & - & $115.822,51$ & $-57.698,79$ & $58.123,72$ & $305.685,66$ & $12.566,01$ & $-165.432,41$ \\
\hline 19 & 2027 & - & $115.822,51$ & $-57.045,19$ & $58.777,32$ & $364.462,97$ & $11.473,87$ & $-153.958,54$ \\
\hline 20 & 2028 & - & $115.822,51$ & $-57.495,81$ & $58.326,70$ & $422.789,67$ & $10.280,73$ & $-143.677,81$ \\
\hline 21 & 2029 & - & $115.822,51$ & $-57.045,19$ & $58.777,32$ & $481.566,99$ & $9.354,54$ & $-134.323,27$ \\
\hline 22 & 2030 & - & $115.822,51$ & $-57.698,79$ & $58.123,72$ & $539.690,71$ & $8.352,61$ & $-125.970,65$ \\
\hline 23 & 2031 & - & $115.822,51$ & $-57.045,19$ & $58.777,32$ & $598.468,03$ & $7.626,67$ & $-118.343,98$ \\
\hline 24 & 2032 & - & $115.822,51$ & $-57.495,81$ & $58.326,70$ & $656.794,73$ & $6.833,59$ & $-111.510,39$ \\
\hline 25 & 2033 & - & $115.822,51$ & $-68.292,85$ & $47.529,66$ & $704.324,39$ & $5.028,08$ & $-106.482,31$ \\
\hline 26 & 2034 & - & $115.822,51$ & $-57.495,81$ & $58.326,70$ & $762.651,09$ & $5.571,36$ & $-100.910,94$ \\
\hline 27 & 2035 & - & $115.822,51$ & $-57.045,19$ & $58.777,32$ & $821.428,41$ & $5.069,44$ & $-95.841,50$ \\
\hline 28 & 2036 & - & $115.822,51$ & $-57.698,79$ & $58.123,72$ & $879.552,13$ & $4.526,47$ & $-91.315,03$ \\
\hline 29 & 2037 & - & $115.822,51$ & $-57.045,19$ & $58.777,32$ & $938.329,44$ & $4.133,07$ & $-87.181,96$ \\
\hline 30 & 2038 & - & $115.822,51$ & $-57.698,79$ & $58.123,72$ & $996.453,16$ & $3.690,39$ & $-83.491,57$ \\
\hline
\end{tabular}

${ }^{1}$ Ano do projeto; ${ }^{2}$ Ano calendário; ${ }^{3}$ Entrada e saída de caixa devido à operação de crédito rural; ${ }^{4}$ Receita bruta das vendas; ${ }^{5}$ Desembolsos; ${ }^{6}$ Fluxo de caixa líquido (ESC+RB-D); ${ }^{7}$ Fluxo de caixa líquido acumulado não descontado; ${ }^{8}$ Fluxo de caixa líquido descontado; ${ }^{9}$ Fluxo de caixa líquido acumulado descontado.

Nota: Taxa de desconto de $10,75 \%$ ao ano. 
Tabela 7. Projeção dos fluxos de caixa do empreendimento com a utilização de recursos próprios, receitas brutas auferidas a partir da venda de animais e entrada de caixa decorrente do arrendamento da terra, com utilização de média geral dos preços corrigidos 2009-2038. Cenário 10

\begin{tabular}{|c|c|c|c|c|c|c|c|c|}
\hline $\mathrm{AP}^{1}$ & $\mathrm{AC}^{2}$ & $\mathrm{EC}^{3}$ & $\mathrm{RB}^{4}$ & $\mathrm{D}^{5}$ & $\mathrm{FCL}^{6}$ & FCL $\left(\mathrm{AND}^{7}\right)$ & $\mathrm{FCL}\left(\mathrm{D}^{8}\right)$ & FCL $\left(\mathrm{AD}^{9}\right)$ \\
\hline 1 & 2009 & - & - & $-12.435,99$ & $-12.435,99$ & $-12.435,99$ & $-15.253,44$ & $-15.253,44$ \\
\hline 2 & 2010 & $87.324,38$ & - & $-303.794,39$ & $-216.470,01$ & $-228.905,99$ & $-239.740,53$ & $-254.993,97$ \\
\hline 3 & 2011 & $87.324,38$ & $12.002,61$ & $-211.653,08$ & $-112.326,09$ & $-341.232,09$ & $-112.326,09$ & $-367.320,06$ \\
\hline 4 & 2012 & $87.324,38$ & $71.359,44$ & $-56.084,89$ & $102.598,93$ & $-238.633,15$ & $92.640,12$ & $-274.679,94$ \\
\hline 5 & 2013 & $87.324,38$ & $117.563,80$ & $-56.992,58$ & $147.895,60$ & $-90.737,55$ & $120.577,92$ & $-154.102,02$ \\
\hline 6 & 2014 & $87.324,38$ & $121.549,59$ & $-59.956,30$ & $148.917,67$ & $58.180,12$ & $109.626,37$ & $-44.475,65$ \\
\hline 7 & 2015 & $87.324,38$ & $120.838,44$ & $-57.044,76$ & $151.118,06$ & $209.298,18$ & $100.448,03$ & $55.972,38$ \\
\hline 8 & 2016 & $87.324,38$ & $115.614,09$ & $-57.493,19$ & $145.445,28$ & $354.743,47$ & $87.293,31$ & $143.265,69$ \\
\hline 9 & 2017 & $87.324,38$ & $115.822,51$ & $-68.292,85$ & $134.854,04$ & $489.597,50$ & $73.080,51$ & $216.346,20$ \\
\hline 10 & 2018 & $87.324,38$ & $115.822,51$ & $-57.698,79$ & $145.448,10$ & $635.045,60$ & $71.170,81$ & $287.517,01$ \\
\hline 11 & 2019 & $87.324,38$ & $115.822,51$ & $-57.045,19$ & $146.101,70$ & $781.147,30$ & $64.551,36$ & $352.068,37$ \\
\hline 12 & 2020 & $87.324,38$ & $115.822,51$ & $-57.698,79$ & $145.448,10$ & $926.595,40$ & $58.024,90$ & $410.093,27$ \\
\hline 13 & 2021 & $87.324,38$ & $115.822,51$ & $-57.045,19$ & $146.101,70$ & $1.072 .697,10$ & $52.628,13$ & $462.721,40$ \\
\hline 14 & 2022 & $87.324,38$ & $115.822,51$ & $-57.495,81$ & $145.651,08$ & $1.218 .348,18$ & $47.373,19$ & $510.094,59$ \\
\hline 15 & 2023 & $87.324,38$ & $115.822,51$ & $-57.045,19$ & $146.101,70$ & $1.364 .449,88$ & $42.907,23$ & $553.001,81$ \\
\hline 16 & 2024 & $87.324,38$ & $115.822,51$ & $-57.698,79$ & $145.448,10$ & $1.509 .897,98$ & $38.569,10$ & $591.570,91$ \\
\hline 17 & 2025 & $87.324,38$ & $115.822,51$ & $-68.292,85$ & $134.854,04$ & $1.644 .752,02$ & $32.288,78$ & $623.859,70$ \\
\hline 18 & 2026 & $87.324,38$ & $115.822,51$ & $-57.698,79$ & $145.448,10$ & $1.790 .200,12$ & $31.445,03$ & $655.304,73$ \\
\hline 19 & 2027 & $87.324,38$ & $115.822,51$ & $-57.045,19$ & $146.101,70$ & $1.936 .301,81$ & $28.520,39$ & $683.825,12$ \\
\hline 20 & 2028 & $87.324,38$ & $115.822,51$ & $-57.495,81$ & $145.651,08$ & $2.081 .952,89$ & $25.672,62$ & $709.497,74$ \\
\hline 21 & 2029 & $87.324,38$ & $115.822,51$ & $-57.045,19$ & $146.101,70$ & $2.228 .054,59$ & $23.252,41$ & $732.750,15$ \\
\hline 22 & 2030 & $87.324,38$ & $115.822,51$ & $-57.698,79$ & $145.448,10$ & $2.373 .502,69$ & $20.901,48$ & $753.651,64$ \\
\hline 23 & 2031 & $87.324,38$ & $115.822,51$ & $-57.045,19$ & $146.101,70$ & $2.519 .604,39$ & $18.957,48$ & $772.609,12$ \\
\hline 24 & 2032 & $87.324,38$ & $115.822,51$ & $-57.495,81$ & $145.651,08$ & $2.665 .255,47$ & $17.064,57$ & $789.673,68$ \\
\hline 25 & 2033 & $87.324,38$ & $115.822,51$ & $-68.292,85$ & $134.854,04$ & $2.800 .109,51$ & $14.265,99$ & $803.939,67$ \\
\hline 26 & 2034 & $87.324,38$ & $115.822,51$ & $-57.495,81$ & $145.651,08$ & $2.945 .760,59$ & $13.912,58$ & $817.852,25$ \\
\hline 27 & 2035 & $87.324,38$ & $115.822,51$ & $-57.045,19$ & $146.101,70$ & $3.091 .862,29$ & $12.601,02$ & $830.453,27$ \\
\hline 28 & 2036 & $87.324,38$ & $115.822,51$ & $-57.698,79$ & $145.448,10$ & $3.237 .310,39$ & $11.326,99$ & $841.780,26$ \\
\hline 29 & 2037 & $87.324,38$ & $115.822,51$ & $-57.045,19$ & $146.101,70$ & $3.383 .412,08$ & $10.273,49$ & $852.053,76$ \\
\hline 30 & 2038 & $87.324,38$ & $115.822,51$ & $-57.698,79$ & $145.448,10$ & $3.528 .860,18$ & $9.234,79$ & $861.288,55$ \\
\hline
\end{tabular}


Todos os cenários nos quais se utilizou o nível mínimo de preços implicam na não aceitação do projeto. Embora represente uma situação extrema - que provavelmente não seja verificada na prática - sinaliza uma tendência típica dos mercados de produtos agropecuários, nos quais ocorre uma deterioração nos termos de troca para alguns insumos de produção. Outra situação seria a da baixa eficiência na utilização das tecnologias de produção, situação na qual elevaria os custos de produção em detrimento às receitas.

Para os cenários nos quais foram utilizados níveis máximos de preços, todos os critérios abalizaram para a aceitação do projeto. Observou-se, para o cenário 7, níveis críticos (Payback Simples, Payback Descontado, valor presente líquido e taxa interna de retorno) em relação aos critérios de aceitação/rejeição. Situação que tende a melhorar para os cenários 8 e 9 , mas ainda assim levando o retorno do investimento para $o$ terço final do horizonte de análise e podendo tornar, na ótica do investidor, a execução do empreendimento arriscada economicamente.

Em todos os cenários analisados, notou-se melhoria nos resultados quando da utilização de financiamento. Esta melhoria deveu-se ao fato de que o custo do capital, ou taxa de empréstimo contratada, ter sido menor que a taxa de atratividade do projeto (taxa de desconto) utilizada na obtenção dos índices de viabilidade econômica, a saber: $6,75 \%$ e $10,75 \%$ respectivamente. Outrossim, a entrada de capital saneou os fluxos líquidos de caixa e, consequentemente, provocou melhora nos índices de viabilidade econômica. Ressalta-se oportunamente a importância dos prazos de carência mais dilatados quando dos pagamentos das parcelas de juros oriundas das obrigações relacionadas à opção de financiamento.

O cenário 10 justificaria a produção sob alta lotação. Apresentou-se como um dos principais motivadores - se não o principal - da utilização do sistema sob alta lotação na pecuária comercial. Proporcionou a possibilidade do uso intensivo da terra e retornos econômicos expressivos da condição de arrendamento da área a ser liberada. Explicitou o alto custo de oportunidade da terra, conforme observado por Füsternau (2004).

$O$ aspecto central para a consideração dos resultados obtidos neste trabalho é que esses são particulares para a infraestrutura considerada, que priorizou a execução de pesquisas.

$\mathrm{Na}$ ótica das instituições sem fins lucrativos, como no caso da Universidade de São Paulo, observou-se a possibilidade da obtenção de resultado que recupere os custos implícitos e explícitos do capital consumido pelos projetos de pesquisa. Esta premissa auxilia a transferência de tecnologias geradas na pesquisa - quando da atividade de extensão - pois subsidia o extensionista de argumentos frente aos produtores que desenvolvem a atividade pecuária com fins lucrativos.

O estudo de viabilidade é o conjunto de informações que antecede à execução de um projeto e tem por objetivo auxiliar o processo de tomada de decisão para um empreendimento. A análise econômica é parte integrante deste estudo. Não constitui garantia de sucesso, porém pode representar menores possibilidades de fracasso, tanto na ótica da produção quanto na decisão do investimento.

Conclui-se que o sistema de produção de pecuária de bovinos de corte - sob alta lotação animal e com ciclo completo de produção - proposto para a implantação de pesquisas zootécnicas foi viável economicamente - sob a ótica comercial - estritamente para os cenários que consideram o nível máximo de projeção 
Rev. Bras. Saúde Prod. Anim., Salvador, v.13, n.1, p.244-257 jan/mar, 2012 http://www.rbspa.ufba.br ISSN 15199940

de preços da arroba da carne (7, 8 e 9) e para o cenário 10 quando adotados os critérios técnicos de aceitação/rejeição de projetos de investimento. A utilização de financiamento via Programa de Crédito Rural do BNDES proporcionou melhora expressiva nos valores monetários e índices utilizados na análise.

\section{REFERÊNCIAS}

AMARAL, R.; FONSECA DE MACEDO, F.; ALCALDE, C.; LINO, D.; BÁNKUTI, F.; MACEDO, F.; DIAS, F.; GUALDA, T. Desempenho produtivo e econômico de cordeiros confinados abatidos com três espessuras de gordura.Revista Brasileira de Saúde e Produção Animal [Online], v.12, n.1, p.155-165, 2011.

ASSUMPÇÃO, T.; PACHEMSHY, J.; ANDRADE, E.; SILVA, N.

Perdas econômicas resultantes de reações vacinais em carcaças de bovinos da raça Nelore. Revista Brasileira de Saúde e Produção Animal [Online], v.12, n.2, p.375380, 2011

BALARINE, O.F.O. O uso da análise de investimentos em incorporações imobiliárias. Revista Produção, v.14, n.2, p.47-57, 2004.

BANCO NACIONAL DE

DESENVOLVIMENTO ECONÔMICO E SOCIAL - BNDES. Programas e fundos. Disponível em: <http://www.bndes.gov.br /SiteBNDES/bndes/bndes_pt/Instituc ional/Apoio_Financeiro/Programas_e Fundos/ >. Acesso em: 7 set. 2010.
BARBIERI, J.; ÁLVARES, A.; MACHLINE, C. Taxa Interna de retorno: controvérsias e interpretações. GEPROS. Gestão da Produção, Operações e Sistemas, v.5, n.4, p.131-142, 2007.

CENTRO DE ESTUDOS E PESQUISA AVANÇADOS EM ECONOMIA APLICADA - CEPEA. Áreas de pesquisa. Disponível em: $<$ http://www.cepea.esalq.usp.br/boi/ ?merc $=2>$. Acesso em: 6 jun. 2010 .

FÜRSTENAU, V. Pecuária de corte: baixos índices zootécnicos e eficiência no setor exportador. Indicadores

Econômicos FEE, v.32, n.1, p.265-292, 2004.

FUNDAÇÃO GETÚLIO VARGAS. IGP-DI índice geral de preços.

Disponível em:

$<$ http://www.ibre.fgv.br/>. Acesso em: 22 jun. 2010.

LIMA, R.; OLIVEIRA LIMA, P.; DUARTE CÂNDIDO, M.; SILVA THÉ PONTES, F.; RUFINO MOREIRA, R.; AQUINO, R.S. Avaliação econômica de dietas líquidas à base de soro de queijo in natura para bezerros. Revista Brasileira de Saúde e Produção Animal [Online], v.12, n.1, p.14-21, 2011.

MARTINS, S.; ROCHA JÚNIOR, V.; CALDEIRA, L.; PIRES, D.; BARROS, I.; SALES, E.; SANTOS, C.; AGUIAR, A.; OLIVEIRA, C. Consumo, digestibilidade, produção de leite e análise econômica de dietas com diferentes volumosos. Revista Brasileira de Saúde e Produção Animal [Online], v.12, n.3, p.691-708, 2011. 
Rev. Bras. Saúde Prod. Anim., Salvador, v.13, n.1, p.244-257 jan/mar, 2012 http://www.rbspa.ufba.br ISSN 15199940

REBOUÇAS, A.; ZANINI, A.;

KIPERSTOK, A.; PEPE, I.;

EMBIRUÇU, M. Panorama das graxarias no Brasil e a inserção do pequeno produtor no agronegócio da carne: aspectos de saúde pública, econômicos e políticos. Revista Brasileira de Saúde e Produção Animal [Online], v.11, n.4, p.1219-1233, 2010.

ROCHA NETO, A.; VELOSO, C.; SILVA, F.; MENEZES, D.; OLIVEIRA, H.; AZEVÊDO, S.; PINHEIRO, A.; OLIVEIRA, A.; COSTA, L.; DE SOUZA, D. Avaliação econômica do confinamento de novilhas leiteiras alimentadas com farelo de cacau na dieta. Revista Brasileira de Saúde e Produção Animal [Online], América do Norte, v.11, n.4, p.10681080, 2010.
RODRIGUES, R. Viabilidade econômica de um sistema de produção pecuária de bovinos sob alta lotação: uso na pesquisa e na pecuária comercial. 2010. 176p. Dissertação (Mestrado em Ciências) Faculdade de Medicina Veterinária, Universidade de São Paulo, Pirassununga.

VIANA, J.G.A.; SOUZA, R.S.; SILVEIRA, V.C.P. Evolução dos preços históricos da bovinocultura de corte do Rio Grande do Sul: Tendência e comportamento dos preços em nível de produtor e consumidor. Ciência e agrotecnologia, v.33, n.4, p.1109-1117, 2009.

Data de recebimento: 10/06/2011

Data de aprovação: 12/12/2011 